\title{
Editorial: the archaeobotany of early rice agriculture in Asia
}

\author{
Leo Aoi Hosoya • Yo-Ichiro Sato • Dorian Q. Fuller
}

Published online: 8 June 2010

(C) Springer-Verlag 2010

Rice is the staple food par excellence of East Asia and the most densely populated landscapes of China, Korea, Japan, Southeast Asia, and South Asia. The origins and spread of rice and the intensification of rice farming is often connected to the development of civilization and ancient states in many parts of this region (Gorou 1984; Bray 1994). While it is widely accepted that China was an independent centre of plant domestication (Bellwood 2005; Barker 2006) and rice was one of its major domesticated crops, the origins of agriculture has received less problemoriented research than in regions like the Near East or Mesoamerica. Much discussion of agricultural origins has had a Western bias, focusing on the origins of wheat, or in America maize, and research by Western scholars on the origins of these crops.

In Japanese scholarship, there has long been an emphasis placed on the divergent traditions of agriculture, environment and culture in western and eastern Eurasia. One source of this thinking is the early twentieth century philosopher Watsuji and his concept of a link between climate and culture (Watsuji 1921, 1961). Watsuji developed a concept of Fudo ("climatic zones"), drawing a distinction between the environment, agricultural traditions and nature of human cultures between Western Eurasia, the zone of mugi (the cereals including wheats and barley) and the zone of rice and monsoons in Eastern Asia. Watsuji's inference was that at opposite ends of Eurasia there have

\footnotetext{
L. A. Hosoya $\cdot$ Y.-I. Sato

Research Institute for Humanity and Nature,

Kyoto, Japan

D. Q. Fuller $(\bowtie)$

University College London,

London, UK

e-mail: d.fuller@ucl.ac.uk
}

been long histories of different traditions of cultural impact on the environments, understandings of the environment and subsistence. Indeed, the accumulated evidence of archaeology suggests that post-Palaeolithic trajectories in East and West Asia were quite different, with varying emphases on grinding and bread-making in the west, where wheat and barley were domesticated, and more technology devoted in boiling and steaming in the east where rice and some millets were domesticated (Fuller and Rowlands 2009). It remains the case, however, that our understanding of agricultural origins and plant domestication in East Asia is far less well-documented and understood by comparison to West Asia, and the work represented in this volume contributes towards increasing parity.

The dispersal of rice farming is often seen as pivotal in the population history of East and Southeast Asia and is linked to the establishment of sedentism and the spread of major language families (Bellwood 2005). Previous syntheses have more often been based on cultural historical archaeology rather than archaeological science, pots rather than the evidence of plants themselves. In recent years, a great deal of new data and new ideas on the origin of rice agriculture in China and its diffusion through East and Southeast Asia has emerged. This is due in part to the growth of systematic archaeobotany in East Asia, with flotation now being practised more often in China and Korea, where such methods were rarely deployed in the region a decade ago. New genetic data have also forced reconsiderations of the existing models of the number of origins and trajectories of spread of rice agriculture. New debates about the number of origins and where they were have emerged from genetic inferences (e.g. Kovach et al. 2007; Fuller and Sato 2008; Vaughan et al. 2008; Zhang et al 2009; Izawa et al. 2009). Genetics is also increasingly providing information on the particular genes that underlie 
adaptations that evolved in the Neolithic or since. Now, cross-disciplinary discussion among archaeobotanists and geneticists is required to take research on the prehistory and history of rice further. This special issue brings together a range of regional archaeobotanical specialists and geneticists to reassess current evidence and to work towards a new synthesis of the origins and spread of early Asian rice.

This issue has seven papers: four are purely archaeological and archaeobotanical, two are genetic and one tries to integrate both. The opening paper by Purugganan (2010) shows how rice genetics can provide histories (or vignettes) of how rice has moved and adapted to new environments, including cultural environments of food preference. One of the vignettes he explores is the evolution of glutinous rice, which characterizes part of the food repertoire of large parts of East and Southeast Asia (see Sakamoto 1996). Tanaka et al. (2010) illustrate the role of ancient DNA, preserved inside ancient rice remains, as a basis for assessing the changing genetic diversity of rice in a particular region. This paper illustrates how increasing advances in techniques of DNA extraction should continue to provide new data about past genetic populations and how these have been altered through cultural history to arrive at the modern geography of varieties and landraces.

The subsequent papers are more archaeological. Papers by Ahn (2010) and Weber et al. (2010) introduce recent research results from Korea and Thailand. They provide further evidence on the diffusion of rice agriculture to East and Southeast Asia from the view of archaeobotany. While Ahn provides an exhaustive synthesis of Korean data, Weber et al. (2010) explore the wider implications of results from a systematic sampling programme at one clutch of sites in central Thailand. Both of these authors touch on the importance of millets as crops that preceded rice and continued alongside rice, reminding us that rice must be placed into a wider economy. Then, Zhao (2010) and Nakamura (2010) update us on recent debates and new research results on early rice in south China. These are also addressed in the last paper by Fuller et al (2010). Zhao, a senior figure in archaeobotanical research in China, provides a review of key recent finds of early rice and his own perspective on recent controversies concerning the beginnings of rice domestication and cultivation. Nakamura (2010) provides an updated synthesis that draws on recent results of a collaborative project between Chinese and Japanese researchers in the Lower Yangtze region. What emerges from these papers on China is that there is now an accepted body of evidence for the gradual emergence of rice agriculture and gradual evolution of fully domesticated rice that culminated perhaps closer to $4,000 \mathrm{BC}$. Thus, it is now clear that the slow evolution of domesticated rice parallels recent realizations about West Asian wheat and barley domestication (Fuller 2007; Purugganan and Fuller
2009; Brown et al. 2009). However, how best to interpret the rather more fragmentary evidence from the Late Pleistocene and Early Holocene, whether as rice-gathering hunters or incipient cultivators, remains an area of scholarly debate and a priority for research. The extent to which these earliest interactions with rice were part of the domestication process is unclear: were there domestication-like preadaptations in some local Pleistocene rice (suggested by Zhao) or did the domestication of rice truly begin later (as suggested by Nakamura and Fuller et al.)? The paper by Fuller et al. (2010) synthesizes genetic evidence and archaeobotanical evidence, as well as that from South Asia, to propose an overall chronological and geographical framework for the development and spread of rice at a pan-Asian scale. They include updated compilations of evidence for the evolution of non-shattering and larger grains (in both India and China). They then suggest that there are 11 main "thrusts" (regional developments of spread events in the early history of rice), and they also highlight the role of hybridization where some of these thrusts have intersected.

One of the challenges in the study of rice is that researchers are dispersed across many countries and separated by languages. Thus, most archaeological research in China, South Korea and Japan is published in the respective languages of those countries, although English is more common as a language of archaeological scholarship in South and Southeast Asia. This special issue represents an effort to bring together, in English, contributions that represent the current thinking and debates in all of these countries and the scholarly literature in the various languages. This is an important step towards an international and macro-regional synthesis. In addition, we have hoped to aid the mutual understanding of archaeobotanists and geneticists and to find consilience and potential collaboration between these different fields in the study of rice origins.

Acknowledgements This issue is based on papers from an international symposium, "Origin of Rice Agriculture and Its Diffusion to Southeast and East Asia", held on 30-31 August 2009 at the Research Institute for Humanity and Nature, Kyoto, Japan, by Sato Project, RIHN (Leader: Yo-Ichiro Sato), with support of the Japanese Society for the Promotion Science (JSPS), Grant-in-Aid for Scientific Research (C) for "Discussion on Chinese early rice agriculture and society from the interdisciplinary view of archaeology and genetics" (Leader: Leo Aoi Hosoya).

\section{References}

Ahn S-M (2010) The emergence of rice agriculture in Korea: archaeobotanical perspectives. Archaeol Anthropol Sci 2(2). doi:10.1007/s12520-010-0029-9

Barker G (2006) The agricultural revolution in prehistory. Oxford University Press, Oxford

Bellwood P (2005) First farmers. Blackwell, Oxford 
Bray F (1994) The rice economies: technology and development in Asian societies. University of California Press, Berkeley

Brown TA, Jones MK, Powell W, Allaby RG (2009) The complex origins of domesticated crops in the Fertile Crescent. Trends Ecol Evol 24:103-109

Fuller DQ (2007) Contrasting patterns in crop domestication and domestication rates: recent archaeobotanical insights from the Old World. Ann Bot 100:903-924

Fuller DQ, Rowlands M (2009) Towards a long-term macrogeography of cultural substances: food and sacrifice traditions in East, West and South Asia. Chinese Review of Anthropology 12:1-37

Fuller DQ, Sato Y-I (2008) Japonica rice carried to, not from, Southeast Asia. Nat Genet 40:1264-1265

Fuller DQ, Sato Y-I, Castillo C, Qin L, Weisskopf A, KingwellBanham E, Song J, Ahn S-M, van Etten J (2010) Consilience of genetics and archaeobotany in the entangled history of rice. Archaeol Anthropol Sci 2(2). doi:10.1007/s12520-010-0035-y

Gorou P (1984) Riz et civilisation. Fayard, Paris

Izawa T, Konishi S, Shomura A, Yano M (2009) DNA changes tell us about rice domestication. Curr Opin Plant Biol 12: $185-192$

Kovach MJ, Sweeney MT, McCouch SR (2007) New insights into the history of rice domestication. Trends Ecol Evol 23:578-587

Nakamura S (2010) The origin of rice cultivation in the Lower Yangtze region, China. Archaeol Anthropol Sci 2(2). doi:10.1007/s12520010-0033-0
Purugganan M (2010) The evolution of rice: molecular vignettes on its origins and spread. Archaeol Anthropol Sci 2(2). doi:10.1007/ s12520-010-0026-Z

Purugganan MD, Fuller DQ (2009) The nature of selection during plant domestication. Nature 457:843-848

Sakamoto S (1996) Glutinous-endosperm starch food culture specific to Eastern and Southeastern Asia. In: Ellen R, Fukui K (eds) Redefining nature. Ecology, culture and domestication. Berg, Oxford, pp 215-231

Tanaka K, Ishikawa R, Honda T (2010) Rice archaeological remains and possibility of DNA archaeology: examples from Yayoi and Heian periods of Northern Japan. Archaeol Anthropol Sci 2(2). doi:10.1007/s12520-010-0036-x

Vaughan DA, Lu B-R, Tomooka N (2008) Was Asian rice (Oryza sativa) domesticated more than once? Rice 1(1):16-24

Watsuji T (1921) Fudo. Iwanami-bunko, Tokyo [in Japanese]

Watsuji T (1961) Climate and culture: a philosophical study (translated from Fudo by G. Bownas). Greenwood, Westport

Weber S, Lehman H, Barela T, Hawks S, Harriman D (2010) Rice or millets: early farming strategies in prehistoric central Thailand. Archaeol Anthropol Sci 2(2). doi:10.1007/s12520-010-0030-3

Zhang L-B, Zhu Q, Wu Z-Q, Ross-Ibarra J, Gaut BS, Ge S, Sang T (2009) Selection on grain shattering genes and rates of rice domestication. New Phytol 184:708-720

Zhao Z (2010) New data and new issues for the study of origin of rice agriculture in China. Archaeol Anthropol Sci 2(2). doi:10.1007/ s12520-010-0028-x 